\title{
O ensino da literatura e suas perspectivas metodológicas no contexto dos Institutos Federais de Educação, Ciência e Tecnologia
}

\author{
Literature teaching and its methodological perspectives in the \\ context of the Federal Institutes of Education, Science and \\ Technology
}

Tatiana Prevedello ${ }^{1}$

\begin{abstract}
Resumo
O ensino de literatura portuguesa, no Brasil, fundamental para a compreensão da matriz identitária sobre a qual foi moldado o caráter literário nacional, tem passando por processos que, em uma primeira instância, visam redefinir as políticas prioritárias em termos de formação básica, a partir dos novos redimensionamentos que, sobretudo, o ensino médio vem recebendo. Nessa perspectiva, objetivou-se investigar junto aos docentes de Língua Portuguesa e Literatura Brasileira (LPLB), que exercem suas atividades nos Institutos Federais de Ciência, Tecnologia e Educação, no Estado do Rio Grande do Sul, quais sejam, Instituto Federal do Rio Grande do Sul - IFRS, Instituto Federal Sul-Rio-Grandense - IFSul e Instituto Federal Farroupilha - IFFar, as metodologias utilizadas no ensino da literatura. Pretendeu-se verificar como os docentes de LPLB desenvolvem, em suas aulas, o ensino de literatura e, de que maneira, a tradição histórica da disciplina dialoga com questões como a formação do cânone nacional. A coleta de dados foi feita por intermédio da aplicação de um questionário eletrônico, constituído de questões objetivas e abertas, o qual buscou realizar um levantamento referente às metodologias aplicadas pelos docentes de LPLB, técnicas de ensino utilizadas e projetos desenvolvidos na área.
\end{abstract}

Palavras-chave: Ensino. Literatura Portuguesa. Institutos Federais.

\begin{abstract}
Teaching Portuguese Literature in Brazil, fundamental for understanding the identity matrix upon which the national literary character was molded, has going through processes that, in a first instance, aims to redefine priority policies in terms of basic training, from the new resizes that, specially, high school has been receiving. In this perspective, the objective was to investigate with teachers of Portuguese Language and Brazilian Literature (PLBL), who exercise their activities at the Federal Institutes of Science, Technology and Education, which are Federal Institute of Rio Grande do Sul - IFRS, Federal Institute Sul-Rio-Grandense - IFSul, and Federal Institute Farroupilha - IFFar, the methodologies used in teaching literature. It was intended to verify how the PLBL teachers develop, in your classes, teaching literature and, in what way, the historical tradition of this discipline dialogues with issues such as the formation of the national canon. Data collection was done through the application of an electronic questionnaire, made up of objective and open questions, which sought to conduct a survey regarding the methodologies applied by PLBL teachers, teaching techniques used and projects developed in the area.
\end{abstract}

Keywords: Teaching. Portuguese Literature. Federal Institutes.

1Doutora em Letras. Colégio Militar de Porto Alegre, Porto Alegre, RS, Brasil. Orcid: https://orcid.org/0000-0002-57427692. E-mail: t_prevedello@hotmail.com

LínguaTec, Instituto Federal de Educação, Ciência e Tecnologia do Rio Grande do Sul, Bento Gonçalves v. 5, n. 2, p. 01-22, nov. 2020.

(cc) $\mathrm{EY}-\mathrm{NC}$ 


\section{Os Institutos Federais e o (não) ensino da literatura: considerações iniciais}

O desenvolvimento do presente estudo foi motivado por diversas variáveis que, atualmente, engendram as metodologias de docência da literatura no ensino médio, mais especificamente no contexto dos Institutos Federais de Ciência, Tecnologia e Educação. Na maioria destas instituições a disciplina de literatura já não possui mais períodos independentes, estando associada à língua portuguesa. Dessa forma, embora existam tópicos na organização programática da disciplina a serem ministrados pelos professores que devem incluir, em seus planos de ensino, conteúdos literários, não há parâmetros específicos que orientem como a literatura deva ser trabalhada em relação à distribuição de sua carga horária, gêneros literários, autores e textos. Nessa conjuntura, apresentou-se, também, a preocupação em investigar como literatura portuguesa, que já correu o risco de ser suprimida da Base Nacional Comum Curricular², é percebida pelos professores, em sua prática docente, e no material disponibilizado pelo Programa Nacional do Livro Didático 3 por meio do Ministério da Educação e Cultura.

Há mais de duas décadas, em 1995, em conferência apresentada no Congresso Brasileiro de Língua e Literatura, na Universidade do Estado do Rio de Janeiro - UERJ, Sérgio Nazar David questionou: "[...] como vai a literatura portuguesa nas escolas de ensino médio? A resposta é que em muitas delas não vai. E se isto acontece quero crer não está suficientemente claro ainda para

\footnotetext{
${ }^{2}$ No início de 2016, a primeira versão apresentada referente à reforma da Base Nacional Comum Curricular, gerou uma profunda polêmica, ao situar, na Área da Linguagens, o ensino da literatura voltado somente para a leitura e apreciação de "textos literários tradicionais da cultura popular, afrobrasileira, africana, indígena e de outros, povos", sem trazer qualquer menção à literatura portuguesa. $\mathrm{O}$ fato, como não poderia deixar de ser, repercutiu de forma negativa e desfavorável na comunidade dos países de língua portuguesa, no contexto da educação nacional e entre os professores e associações que primam pelo ensino desta literatura, o que gerou veementes posicionamentos, enfatizando-se as manifestações da Associação Brasileira de Professores de Literatura Portuguesa - ABRAPLIP. A segunda versão da Base Nacional Comum Curricular, cuja proposta preliminar foi revista e, segundo dado estatístico disponibilizado no site no MEC, recebeu 12.226 .510 contribuições, trouxe algumas consideráveis reformulações em relação ao texto anterior situando, dessa vez, a importância da Literatura Portuguesa.

${ }^{3}$ Conforme o Portal do MEC "o Programa Nacional do Livro e do Material Didático (PNLD) é destinado a avaliar e a disponibilizar obras didáticas, pedagógicas e literárias, entre outros materiais de apoio à prática educativa, de forma sistemática, regular e gratuita, às escolas públicas de educação básica das redes federal, estaduais, municipais e distrital e também às instituições de educação infantil comunitárias, confessionais ou filantrópicas sem fins lucrativos e conveniadas com o Poder Público. O Decreto n 9.099, de 18 de julho de 2017, unificou as ações de aquisição e distribuição de livros didáticos e literários, anteriormente contempladas pelo Programa Nacional do Livro Didático (PNLD) e pelo Programa Nacional Biblioteca da Escola (PNBE)". Disponivel em: <http://portal.mec.gov.br/component/content/article?id=12391:pnld> Acesso em: 03 jul. 2020.
}

LínguaTec, Instituto Federal de Educação, Ciência e Tecnologia do Rio Grande do Sul, Bento Gonçalves v. 5, n. 2, p. 01-22, nov. 2020. 
aqueles professores que passam ao largo da literatura portuguesa que razões teriam para não fazêIo" (DAVID, 1995, p. 87).

A partir da interrogação suscitada por Nazar David, os propósitos da nossa investigação também consideram as inúmeras reformas pelas quais o ensino médio passou, nas últimas décadas, por meio das quais a literatura veio, gradativamente, perdendo espaço até ser, praticamente, suprimida dos currículos da educação básica, ao ser associada ao ensino de língua portuguesa. Nos Institutos Federais de Ciência, Tecnologia e Educação essa situação é permeada por uma condição dicotômica, uma vez que, embora essas instituições de ensino, em virtude do investimento recebido, apresentem boas condições estruturais e profissionais adequadamente capacitados, o caráter tecnicista desta modalidade educacional compromete, sobremaneira, as metodologias de ensino de literatura desenvolvidas pelos profissionais das Letras.

A indagação que motivou a pesquisa coincidiu com o meu ingresso na instituição, em 2016, quando pude observar que os professores ensinavam, ou não, a literatura de forma assimétrica e assistemática em relação à língua portuguesa, constatando-se as mais divergentes metodologias. Sob a forma de uma pesquisa qualiquantitativa ${ }^{4}$, decidiu-se fazer um mapeamento, entre os professores da área de Letras, que atuam nos cursos técnico integrado ao ensino médio ${ }^{5}$ nos Institutos Federais de Ciência, Tecnologia e Educação do Estado do Rio Grande do Sul, os quais abrangem três instituições: Instituto Federal do Rio Grande do Sul (IFRS) ${ }^{6}$, Instituto Federal Sul-RioGrandense (IFSul)7 e Instituto Federal Farroupilha (IFFar) ${ }^{8}$, acerca das metodologias empregadas no ensino de literatura. Entre os objetivos que nortearam o desenvolvimento da pesquisa buscou-

\footnotetext{
${ }^{4}$ A pesquisa, financiada pelo Programa de Apoio à Iniciação Científica no Ensino Técnico (modalidade integrado) PAIC-ET1, foi desenvolvida no Instituto Federal Farroupilha - Campus São Borja, entre agosto de 2017 a janeiro de 2020.

${ }^{5}$ Curso regular de Ensino Médio associado à formação profissional técnica.

6 O Instituto Federal de Educação, Ciência e Tecnologia do Rio Grande do Sul (IFRS) possui dezessete campi: Bento Gonçalves, Canoas, Caxias do Sul, Erechim, Farroupilha, Feliz, Ibirubá, Osório, Porto Alegre, Restinga (Porto Alegre), Rio Grande e Sertão e, em processo de implantação: Alvorada, Rolante, Vacaria, Veranópolis e Viamão. A Reitoria é sediada em Bento Gonçalves.

7 O Instituto Federal de Educação, Ciência e Tecnologia Sul-rio-grandense (IFSul), cuja sede administrativa está localizada em Pelotas, é formado por quatorze campi: Pelotas, Pelotas-Visconde da Graça, Sapucaia do Sul, Charqueadas, Passo Fundo, Bagé, Camaquã, Venâncio Aires, Santana do Livramento, Sapiranga, Lajeado, Gravataí, Jaguarão e Novo Hamburgo.

8 O Instituto Federal de Educação, Ciência e Tecnologia Farroupilha - IF Farroupilha, cuja Reitoria está em Santa Maria, é composto por onze campi: Alegrete, Frederico Westphalen, Jaguari, Júlio de Castilhos, Panambi, Santa Rosa, Santo Ângelo, Santo Augusto, São Borja, São Vicente do Sul, Avançado Uruguaiana.
} 
se verificar a forma como o ensino de literatura, que atualmente está associado à língua portuguesa, é abordado no contexto do ensino médio, a fim de diagnosticar o modo como ocorre a integração entre ambas as disciplinas. Procuramos investigar a metodologia utilizada pelos professores na docência da literatura, com o propósito de realizar um levantamento concernente aos recursos didáticos empregados na elaboração das aulas. Nessa direção, desejou-se realizar uma apuração relativa à concepção hermenêutica dos professores no ensino de literatura, considerando os vínculos com a tradição histórico-cultural, a matriz identitária que moldou 0 caráter das letras nacionais e as atuais perspectivas de produção literária. Por fim, nos propusemos analisar qual é a expressão da literatura portuguesa, considerando o seu papel na formação da matriz identitária das letras nacionais, no ensino de literatura nos Institutos Federais, e como a mesma é explorada em sua perspectiva histórica e contemporânea.

\section{2 (Des)razões para (não) ensinar literatura}

Pensar sobre a organização hermenêutica do ensino da literatura, no Brasil, construído no âmbito do espaço da sala de aula, requer um trabalho que remeta às origens que configuraram 0 sistema educacional brasileiro. Assim, a recepção da literatura portuguesa no país esteve profundamente imbricada a uma série de elementos que incluem, a partir do princípio do movimento de Independência, no século XIX, o nascimento de um antilusitanismo expressivo, o qual se tornou mais veemente na década de 1830, posterior a abdicação de D. Pedro I. Nesse contexto, conforme avaliação de Regina Zilberman (2002, p. 27):

Mais do que qualquer outra modalidade artística, competiu à literatura exercer o papel de avalista da independência, desde que passasse atestado de nacionalidade brasileira. Pode-se perguntar por que se atribuiu à literatura essa função, pois as condições culturais não recomendavam: predominava a escravidão de negros; mesmo entre a população branca grassava 0 analfabetismo, e a imprensa tinha sido proibida até 1808, ano em que o Príncipe Regente, D. João, transferiu a Corte de Lisboa para o Rio de Janeiro, proibição que obrigou os poucos escritores nascidos na colônia a disputar, no Velho Mundo, os prelos portugueses. Além disso, faltavam escolas, sendo que a expulsão dos jesuítas, no século XVIII, durante a administração pombalina, responsável pelo sistema de ensino mais eficiente do período colonial, fragilizara ainda mais a organização educacional na América Latina. 
Nessa conjuntura os intelectuais brasileiros que chegaram à fase adulta no decorrer do movimento separatista, e contribuíram para que o mesmo se efetivasse, aparentemente ignoraram tais problemas, pois optaram em seguir "a tendência romântica de seu tempo, atribuindo à literatura - em especial, à fiçãa histórica - a tarefa de representar a nação, fixada por meio da manifestação da cor local [...]" (ZILBERMAN, 2002, p. 27). Prosseguindo a análise relativa ao antilusitanismo, que permeou as primeiras décadas subsequentes à Independência, Zilberman aponta dois fatores primordiais, os quais se tornaram iminentes nessa época e redefiniram os rumos da História da Literatura no Brasil. 0 primeiro deles destaca a rejeição portuguesa, no âmbito escolar brasileiro. Os livros portugueses mantinham no Brasil um mercado significativo, pois aqui circulavam obras publicadas em Lisboa e no Porto, as quais se destinavam aos estudantes brasileiros. Tornou-se necessário, na visão dos intelectuais que precisavam demarcar o seu território nas Letras nacionais, bradar contra essa literatura estrangeira, como manifesta José Veríssimo em A educação nacional, redigida em 1890, logo após a proclamação da República. No texto, Veríssimo utiliza do adjetivo "estrangeira" para (des)qualificar, em meio às críticas que tece, a literatura de autores portugueses: "Seja-me permitida uma recordação pessoal. Os meus estudos feitos de 1867 a 1876 foram sempre em livros estrangeiros. Eram portugueses e absolutamente alheios ao Brasil os primeiros livros que li. [...] E assim foi sem dúvida para toda a minha geração" (VERISSIMO, 1906, p. 4).

Tratando os autores portugueses como estrangeiros, Veríssimo sentenciou que a língua nacional precisava, na escola, ser estudada por intermédio das obras de escritores que nasceram no território brasileiro sendo, portanto, necessária a reformulação dos manuais didáticos. Todavia, isso não aconteceu na segunda metade do século XIX, período evidenciado pelo crítico paraense, uma vez que, desde a alfabetização, os brasileiros eram consumidores potenciais de livros didáticos provenientes de Portugal e formaram, diante da ex-metrópole, um mercado que atraiu e gerou significativos lucros. É importante registrar, também, que os livros portugueses custavam menos que os brasileiros, o que comprometia a produção nacional (ZILBERMAN, 2002). Esse aspecto, de caráter notadamente político e econômico, desencadeou uma competição que acabou por se travar nos bancos escolares, onde eram disputadas as leituras e preferências de gosto, considerando-se indesejados os lusitanos.

A Universidade brasileira surgiu posteriormente à proclamação da independência nacional, de modo que, em 1827, foram criados os cursos de Direito em São Paulo e Olinda, sendo que este 
último posteriormente foi transferido para Recife. No decorrer do século XIX também foram implantadas as faculdades de Medicina, no Rio de Janeiro e em Salvador, e a Politécnica, também na Corte. Ensinava-se literatura em colégios, tal como o Pedro II, o qual foi fundado em 1837, no Rio de Janeiro, e preparava para o ensino superior. No momento em que foram organizados os programas dos primeiros cursos de Letras, o modelo seguido era o consolidado nas escolas secundaristas, que se apoiavam em duas diretrizes: a retórica e a poética, sob uma perspectiva, cujo passado ilustre remontava à antiguidade greco-romana; e, sob outra, a história da literatura que, recentemente havia sido estabelecida. Enquanto os livros de retórica e poética podiam ser traduzidos ou adaptados de modelos europeus, as histórias da literatura precisavam ser elaboradas a partir de um marco zero. $O$ respectivo projeto envolveu a geração romântica e se estendeu até a consolidação da crítica científica desenvolvida por Sílvio Romero, organizador de uma História da literatura brasileira, a qual foi publicada em 1888 e considerada a primeira do gênero (ZILBERMAN, 2002, p. 38).

Nesse ponto reside o segundo argumento destacado por Zilberman (2002): as obras que seguiram o modelo da publicação de Veríssimo deveriam configurar a formação de um cânone, que é o da literatura nacional. Todavia, para atingir o cânone nacional, é necessário seguir o caminho da tradição portuguesa, na qual estava incluída a brasileira: "Por essas e outras razões, as histórias da literatura desde então elaboradas no Brasil elegem como matéria inicial de exposição a delimitação de seu objeto, separando o âmbito nacional e o "estrangeiro", a saber, a literatura portuguesa; depois, tratam de definir a "nacionalidade" dessa literatura, verificando que traços a particularizaram diante da tradição europeia, em especial da lusitana" (ZILBERMAN, 2002, p. 39).

O texto de abertura da História da literatura brasileira: de Bento Teixeira (1601) a Machado de Assis (1908), de José Veríssimo, publicado em 1916, mostra de forma radical os contornos definitivos e as particularidades do objeto que defende e, simultaneamente, apresentando a grande diferenciação da literatura nacional em relação à portuguesa:

A literatura que se escreve no Brasil é já a expressão de um pensamento e sentimento que se não confundem mais com o português, em forma que, apesar da comunidade da língua, não é mais inteiramente portuguesa. É isto absolutamente certo desde o Romantismo, que foi a nossa emancipação literária, seguindo-se naturalmente à nossa independência política (VERÍSSIMO, 1963, p. 3). 
Seguem-se algumas páginas e Veríssimo determina a periodização da história literária, sustentada no fundamento da autonomia, pois "as duas únicas divisões que legitimamente se podem fazer no desenvolvimento da literatura brasileira, são, pois, as mesmas da nossa história como povo: período colonial e período nacional" (VERÍSSIMO, 1963, p. 6). O posicionamento imprime a divisão e condiciona, a partir de então, os intercâmbios entre Brasil e Portugal ao estado de marginalidade nos estudos literários, de modo que o trabalho passa a marcar as características da identidade nacional nos autores nascidos no Brasil posteriormente à independência política.

Sintetizando as consequências desse movimento nacionalista, que teve as suas origens a partir da década de 1830 do século XIX, é possível verificar que o ensino da literatura, o qual moveuse dos colégios para as universidades e retornou para a escola secundária, está fundamentado em uma perspectiva historiográfica. A mesma evidencia, de uma parte, 0 amalgamento que houve no princípio da produção literária nacional ao patrimônio português e, de outra, a sua progressiva liberação e até superação, tal como tem se tem verificado em relação a forma como a literatura é trabalhada no atual ensino médio. Vítima de sucessivas reformas que foram restringindo o espaço de circulação literária em sala de aula, essa modalidade educacional pode, se assim desejar, suprimir as aulas de literatura.

Em decorrência desses inúmeros fatores que legam à literatura brasileira a condição de literatura nacional e deslocam a literatura portuguesa para o lugar de estrangeira, aparentemente, não faz sentido que a mesma seja abordada no contexto do ensino médio, sobretudo, após 0 processo que mobilizou a exclusão da literatura portuguesa dos cursos de Letras. 0 movimento, que foi estimulado na primeira metade dos anos de 1980, objetivou a retirada da literatura portuguesa do currículo mínimo e obrigatório dos cursos de graduação em Letras, que conduziram 0 ápice do processo de rejeição dessa literatura. Em análise publicada no jornal Zero Hora, ainda em 28 de janeiro de 1985, sob o sugestivo título "Para que Literatura Portuguesa?", Irmão Elvo Clemente, professor fundador do primeiro programa de pós-graduação da Faculdade de Letras da PUCRS, destaca:

Os anos de 1983 e 1984 notabilizam-se pelas polêmicas levantadas no Brasil e em Portugal em torno do currículo de Letras no ensino universitário; houve muitos entusiasmos e acaloradas discussões e radicalizações. O Conselho Federal (hoje: Nacional) de Educação chegou a aprovar a proposta de Afrânio Coutinho. Com isso, 0 
ilustre professor e historiador da Literatura de Língua Portuguesa celebrizou-se por sua posição antilusitana [...]. Teve a grande vantagem de despertar os colegas das Letras e das implicações das mudanças do mesmo para o futuro próximo e remoto [...]" (ZERO HORA, 1985, p. 5).

A consequência da gradativa exclusão da literatura portuguesa do currículo dos cursos de Letras não poderia deixar de repercutir nas práticas de ensino de literatura que se tornaram vigentes a partir de então. Os profissionais da área, desprovidos da formação acadêmica que Ihes traria a habilitação necessária para realizar as pontes de interlocução entre a literatura portuguesa e a brasileira acabaram, dessa forma, desprovidos da percepção adequada que thes permitiria estabelecer o respectivo diálogo entre ambas as culturas.

\section{0 contexto dos Institutos Federais e o ensino da literatura}

A compreensão das perspectivas metodológicas relativas à abordagem da literatura no contexto dos Institutos Federais de Educação, Ciência e Tecnologia sugere que, primeiramente, sejam realizados breves apontamentos concernentes à história dessa modalidade de ensino na educação brasileira. Diversas reflexões referentes à educação profissional no Brasil têm sido desenvolvidas em decorrência da implantação dos Institutos Federais de Educação (IFs), a partir de 2008, nos quais se encontram os cursos técnicos, integrados ao ensino médio. A história da educação profissional no Brasil iniciou por meio do Decreto nº 7.566, de 23 de setembro de 1909, no qual o presidente da república, Nilo Peçanha, implantou diversas escolas direcionadas à formação profissional, na época denominadas como Escola de Aprendizes Artífice.

As escolas de Aprendizes Artífices foram transformadas, depois, nos liceus industriais, os quais, a partir de 1942, passaram a ser denominados como escolas industriais e técnicas e, em 1959, tornam-se escolas técnicas federais, que se definem como autarquias. Nessa época surgiu a rede de escolas agrícolas, que passaram a ser nomeadas como Escolas Agrotécnicas Federais, organizadas de acordo com um modelo de escola-fazenda e vinculadas ao Ministério da Agricultura. Em 1967, o Ministério da Educação e Cultura assumiu o gerenciamento das escolas-fazenda, as quais se tornam escolas agrícolas. Na década de 1990 diversas escolas técnicas federais foram transformadas em CEFET - Centro Federal de Educação Tecnológica, as quais vieram a formar a 
base do sistema nacional de educação tecnológica, o qual foi instituído em 1994. Uma grave crise se instaurou nessa modalidade de ensino, a partir de 1998, pois o governo federal proibiu a construção de novas escolas federais. Assim, iniciou em 2004 uma reformulação das políticas federais direcionadas à educação profissional e tecnológica, que principiou com a retomada da oferta de cursos técnicos integrados com o ensino médio e, logo após, em 2005, com a modificação na lei que impossibilitava a expansão da rede federal.

O projeto dos Institutos Federais, publicado em Diário Oficial da União em dezembro de 2008, foi sancionado pelo presidente da república em dezembro do mesmo ano. Essa mudança trouxe como resultado a publicação da Lei 11.892, de 29 de dezembro de 2008, a qual criou, no âmbito do Ministério da Educação, um novo modelo de instituição de educação profissional e tecnológica. Foram implantados, a partir do potencial instalado nos CEFET, escolas técnicas e agrotécnicas federais e escolas vinculadas às universidades federais, além dos Institutos Federais de Educação, Ciência e Tecnologia, gerando uma rede voltada à educação técnica de nível médio e superior.

Desde o advento das Casas de Educandos e Artífices, no século XIX, os cursos de formação profissional, no Brasil, são direcionados à qualificação das classes menos favorecidas. Considerando que a elite encontrava nas universidades a formação intelectual para cargos de decisão, as classes sociais menos privilegiadas optavam pelos cursos técnicos como um meio de acesso ao mercado de trabalho. Diante desse paradigma, o desenvolvimento de uma análise sobre as ideologias que fundamentam o ensino técnico brasileiro contemporâneo, precisa levar em consideração o contexto do qual o mesmo é proveniente e as influências que recebeu, incluindo-se nesse âmbito o treinamento das classes desprestigiadas para o mercado do trabalho; a ênfase atribuída pela pedagogia tecnicista americana adotada no Brasil a partir da segunda metade do século XX; a repressão vivida no decorrer do regime militar brasileiro e a ótica coorporativa, mercadológica e capitalista.

Nesse cenário, é visível que a formação profissional não dedicou atenção e importância às disciplinas voltadas para a reflexão, tais como a filosofia e sociologia; ou para a criatividade e imaginação, como as artes, música e literatura. Por essa razão, a respectiva qualificação profissional é desprovida de uma formação consistente direcionada ao saber reflexivo e cultural. 
Observa-se, ainda, que o ensino técnico, no país, tem se voltado para uma formação desprovida de epistemologia, cujos objetivos se enquadram no utilitarismo, destituído de valor à reflexão e ao estímulo do potencial criativo. Desse modo, a inexistência de uma dedicação especial ao estudo de textos literários na Educação Básica brasileira amplia-se para um processo de sublimação, imperceptibilidade e possível apagamento do ensino da literatura, já desvinculada da matriz identitária portuguesa.

No ensino técnico integrado as disciplinas do ensino médio, que configuram a formação geral, principalmente filosofia, sociologia, música, arte e literatura, apresentam a tendência a serem diminuídas, sendo consideradas apenas um suporte para as disciplinas técnicas, uma vez que essas representam o autêntico objetivo de um curso profissionalizante. A desvalorização do estudo da literatura gera, incontestavelmente, uma pergunta de caráter utilitarista, quando se questiona qual é a importância da respectiva disciplina para a formação profissional. Consoante a todas essas questões de caráter político e histórico, Feijó (2012, p. 154-155) realiza uma interessante reflexão sobre a gradativa perda de espaço da literatura na educação:

Os estudos literários estão perdendo e, podemos calcular, vão perder progressivamente importância. [...] agora há novas produções artísticas e culturais tão legítimas e legitimadas como a literatura. [...] a Antiga Aliança entre o Estado e os estudos da literatura (nacional) através da escola quebrou: na atualidade, aquela principal missão que eles tinham, a de existirem com independência do que neles se dissesse, porque eram uma fórmula bem sucedida de fomentar elementos identitários e de coesão nacionais, e a secundária de formarem em determinados valores projetados em autores e textos, foi substituída. A seleção nacional de futebol ou a TV são veículos mais importantes para essa coesão e identidade, para renová-la ou ativá-la se falta fizer.

Leyla Perrone-Moisés, no artigo "Literatura para todos", publicado em Literatura e sociedade, observa, ainda no princípio da década de 2000, o processo de dissolução da literatura, considerando que a mesma "como disciplina escolar e universitária, parece ameaçada a desaparecer" (2006, p. 17). E, assim, prossegue a sua análise:

[...] entre 2001 e 2002, notou-se o "desaparecimento" da disciplina Literatura no ensino médio de vários estados brasileiros. 0 ensino da literatura foi substituído por ou diluído sob a fórmula "comunicação e expressão". O sumiço da literatura provocou alguns protestos isolados. Mas não aconteceu nenhum movimento geral de repúdio a esse "desaparecimento", nenhum abaixo-assinado de alcance nacional. [...]

LínguaTec, Instituto Federal de Educação, Ciência e Tecnologia do Rio Grande do Sul, Bento Gonçalves v. 5 , n. 2, p. 01-22, nov. 2020. 
Quem se dispuser a dedicar algumas horas a leitura dos documentos do Ministério da Educação brasileiro, referentes ao ensino da literatura, terá algumas surpresas. A primeira é a de verificar que essa área não se chama mais "Língua e literatura", mas "Linguagens, Códigos e suas Tecnologias". O título já diz muito. Estamos em tempos de "linguagens" no plural, isto é, multimídia, e, entre as linguagens, a verbal é apenas uma, e não a mais importante. Múltiplas linguagens supõem múltiplos códigos. E o domínio desses códigos não é considerado como sendo da ordem do conhecimento, mas da tecnologia. $\mathrm{O}$ documento do MEC tem como finalidade "delimitar a área", com base na proposta para o Ensino Médio, cuja diretriz está registrada na Lei de Diretrizes e Bases da Educação Nacional no 9.394196 e no Parecer do Conselho Nacional da Educação/Câmara de Educação Básica no 15/98 (PERRONE-MOISÉS, 2006, p. 19-21).

No âmbito nos Institutos Federais esse processo de dissolução já estava, de certo modo, consolidado, uma vez que o ensino da literatura foi associado ao componente curricular denominado Língua Portuguesa e Literatura Brasileira, de modo que, no contexto do ensino médio, a carga horária da respectiva disciplina pressupõe entre dois e quatro períodos semanais de, aproximadamente, 50 minutos, de acordo com a especificidade de cada curso técnico. Neste espaço, devem ser desenvolvidos os tópicos de ensino de língua portuguesa e produção textual, previstos para cada série do ensino médio, introduzindo-se, conforme rezam os manuais elaborados a partir da final do século XIX, que seguiram o modelo de Veríssimo (1906), a inclusão da literatura de acordo com a sua periodização histórica. Como não existem critérios objetivos que pautam o ensino da literatura, os parâmetros metodológicos de desenvolvimento das aulas ficam sob a responsabilidade do professor, dimensionada pela sua afinidade temática ou formação acadêmica, já que o ingresso na docência dos Institutos Federais não pressupõe habilitação específica na área de literatura. Apresenta-se, assim, uma maneira um tanto quanto aleatória quanto ao modo como 0 ensino da literatura, condensado na mesma disciplina de língua portuguesa, é desenvolvido. Passase por uma abordagem equitativa em relação aos demais tópicos pressupostos pela disciplina de Língua Portuguesa e Literatura Brasileira, a breve menção da periodização literária, incluindo autores, obras principais, características de cada movimento literária ou supressão completa. Sob outra perspectiva, o material fornecido pelo Programa Nacional do Livro Didático para o Ensino Médio (PNLEM), vincula a abordagem da literatura portuguesa à brasileira, mantendo uma relação, senão de dialogismo, pelo menos de causalidade, entre as raízes históricas que originaram as primeiras expressões literárias nacionais, incluindo, na perspectiva contemporânea, as literaturas africanas. Todavia, observa-se que, se o espaço destinado ao ensino da literatura nacional tem sido 
gradativamente reduzido e limitado, isso quando ocorre a sua abordagem, às informações relativas a tópicos reduzidos, concernentes à periodização cronológica, características gerais dos movimentos, seus principais representantes e obras. A articulação com a história da literatura portuguesa e sua representatividade como matriz identitária sob a qual a literatura nacional foi moldada expira em fase terminal, quando já não se extinguiu nessa modalidade de ensino.

\section{0 ensino da literatura nos Institutos Federais do Rio Grande do Sul: resultados e discussões}

A pesquisa foi desenvolvida em duas modalidades, uma vez que envolveu, em um primeiro momento, uma sistematização bibliográfica e documental e, em seguida, uma análise exploratória. A investigação, desenvolvida entre agosto de 2017 a janeiro de 2020, foi de natureza qualiquantitativa e teve como sujeitos participantes os professores de Letras $^{9}$, os quais ministram a disciplina de Língua Portuguesa e Literatura Brasileira na rede de Institutos Federais do Estado do Rio Grande do Sul, composta pelo IFRS, IFSul e FFar.

Na primeira etapa foi feito um levantamento concernente às principais publicações voltadas para a história do ensino da literatura no país. Pretendeu-se investigar em livros, documentos históricos e pesquisas realizadas sobre como foi formado o sistema literário nacional, quais foram suas origens e influências e como foi implantado nas escolas. Posteriormente, procurou-se sistematizar as leis que implementaram os estudos literários no ensino médio, bem como os documentos que redigem as alterações que essa disciplina foi sofrendo no decorrer do tempo até ser associada à língua portuguesa e, em muitos casos, suprimida do ensino médio. Da mesma forma, foram analisados os documentos relativos à distribuição da grade curricular nos Institutos Federais, a partir de sua criação, contemplando o espaço destinado à literatura.

A parte exploratória da pesquisa constou da aplicação de um questionário, composto de perguntas abertas e fechadas, referente à importância atribuída à disciplina de literatura, uma vez

\footnotetext{
9 Optarem em responder o questionário cerca de 70 professores, o que corresponde, aproximadamente, a um terço dos docentes de Letras que integram a rede dos Institutos dos Institutos Federais no Rio Grande do Sul.
} 
que ela está vinculada à língua portuguesa, e procedimentos metodológicos adotados pelos professores que ministram a respectiva disciplina.

A primeira versão do questionário foi aplicada com o propósito de obter os dados da pesquisa junto aos docentes de Letras dos Institutos Federais de Ciência, Tecnologia e Educação, no estado do Rio Grande do Sul e passou por um procedimento de testagem. Nessa etapa, participaram do teste um grupo de professores provenientes de um campus de cada um dos Institutos Federais do Rio Grande do Sul. Diante dos resultados obtidos nesta primeira fase, foram feitas as adequações que se julgaram pertinentes, a fim de se preparar a versão definitiva do respectivo questionário, o qual foi aplicado de maneira subsequente. Os professores foram convidados a responder um questionário eletrônico, relativo à metodologia de ensino empregada em suas aulas de Língua Portuguesa e Literatura Brasileira, cujo enfoque foi a forma como a literatura que, nos últimos anos está associada à língua portuguesa, é abordada em sala de aula.

A considerar que, em termos de organização curricular da disciplina de Língua Portuguesa e Literatura Brasileira, não existem parâmetros metodológicos precisos que norteiam a forma como a literatura é dimensionada no ensino médio, quando questionados sobre o enfoque dedicado a esse aspecto da disciplina constatou-se que $31,4 \%$ dos professores ensinam literatura de forma proporcional à língua portuguesa; $28,6 \%$ apresentam os tópicos referentes à literatura de modo esquemático, mas englobando todo o conteúdo programático previsto para o ensino médio; $14,3 \%$ dão ênfase maior à literatura em relação à língua portuguesa; 11,4\% de forma inferior à língua portuguesa; e 14,3\% apresentaram posicionamentos diferentes às alternativas disponibilizadas no questionário. Alguns professores afirmaram que a carga horária da disciplina permite abordar a literatura apenas de maneira superficial; outros destacaram mencionar algumas informações básicas relativas às questões literárias ou fazer uma contextualização genérica. Foi observado, por alguns professores que, considerando a carga horária da disciplina composta por três períodos semanais, procuram concentrar esse tempo para poder realizar um trabalho de leitura mais aprofundado. Assim, organizam um encontro de três períodos seguidos voltados apenas à literatura a cada três semanas. Outras estratégias foram destacadas, tal como a descrita a seguir:

[...] se a pergunta se refere ao ensino de historiografia literária, eu diria que há pouco espaço para isso em sala de aula. Contudo, focalizo a formação do leitor literário por meio da proposição de leituras literárias curtas em sala de aula (crônicas, contos, 
enquetes, poemas, etc.) e de leituras literárias longas em momentos extra-classe (romaneces, graphic novels, biografias, etc). Neste último caso, mensalmente, alunos se reúnem em grupo de pessoas que estão lendo os mesmos livros e os discutem seguindo um roteiro de tarefas que eu proponho, na condição de professor e leitor mais experiente. $(\mathrm{R} 1)^{10}$

Quando questionados se consideram importante as projeções da literatura portuguesa sobre a literatura brasileira $66,7 \%$ dos docentes responderam "sim", justificando ser necessário contextualizar o ensino de literatura e, para isso, é preciso ultrapassar a literatura brasileira, além de ser importante para os alunos compreenderem melhor a literatura nacional, tal como observamos no seguinte posicionamento:

A literatura portuguesa é muito variada e originou algumas das formas de pensamento que perduram até hoje, como a tradição de amor sublime/platônico e do amor carnal, expresso nas cantigas medievais e presente hoje no cotidiano por meio de letras de músicas, por exemplo. Cânones da literatura brasileira e portuguesa que são retomados em processos de intertextualidade, escritores portugueses que deram início à literatura brasileira, leitmotivs recorrentes constituem razões para que, sempre que possível, a literatura portuguesa seja estudada juntamente com a brasileira. (R1)

Enquanto isso, 33,3\% afirmaram que as projeções da literatura portuguesa não são importantes para a literatura brasileira, em virtude de fatores como: a falta de tempo para ver as duas literaturas; o fato de, nos últimos cem anos, a literatura brasileira ter influenciado mais a literatura portuguesa do que o contrário; o Brasil ter uma história de desdobramentos identitários em constante conflito com referenciação à Europa. Outros posicionamentos refletem bastante o espírito tecnicista dos Institutos Federais:

No ensino médio, não acredito que seja oportuno tal aprofundamento. (R2)

Acho que o foco deve ser a leitura e a produção textual de diferentes gêneros do discurso, não apenas literários. Acaba que o leque de gêneros a ser trabalhado é bastante amplo. No âmbito desse leque os gêneros da esfera literária ocupam apenas uma parte. Por isso, acaba ocorrendo uma projeção maior da língua portuguesa sobre a literatura [...]. (R3)

Prefiro aprofundar a interpretação de textos de literatura brasileira para desenvolver a competência da leitura. Incluir a literatura portuguesa sobrecarrega os conteúdos e a aula se torna aula de história da literatura, e não da literatura propriamente dita. (R4)

${ }_{10}$ Como os sujeitos não foram identificados na aplicação do questionário, convencionou-se utilizar a letra $\mathrm{R}$, como indicativo de resposta, e numerá-las, ordinalmente, a cada questão aqui apresentada.

LínguaTec, Instituto Federal de Educação, Ciência e Tecnologia do Rio Grande do Sul, Bento Gonçalves v. 5 , n. 2, p. 01-22, nov. 2020. 
Ao serem questionados sobre a relevância em mencionar a literatura portuguesa no contexto das aulas, considerando que a disciplina ministrada pelos docentes é Língua Portuguesa e Literatura Brasileira, 56,4\% veem ser importante, em virtude das condições históricas que envolveram a constituição da língua portuguesa e as relações de identidade que pairam sobre a formação literária no Brasil e em Portugal; 15,4\% não acreditam na relevância do nome da disciplina ao contexto de suas aulas: Não, pois acredito que as possibilidades de estudos literários não devam estar condicionadas às escolas normativas e à nacionalidade dos autores. (R1); 12,8\% consideram parcialmente relevante; e outros $15,4 \%$ posicionam-se de outra forma:

Em tarefas de leituras literárias, que [...] são o foco de minha prática, proponho que alunos leiam textos de variadas 'origens'. Assim, há, nas listas de livros que proponho aos alunos, literatura brasileira, portuguesa, africana de língua portuguesa e alguns clássicos da literatura ocidental. (R2)

Tenho dois períodos semanais de literatura. Não abordo a literatura portuguesa porque, dentro desse curto tempo, prefiro trabalhar a interpretação de textos em lugar de listas de livros e autores. (R3)

Sobre a utilização do livro didático nas aulas de Língua Portuguesa e Literatura Brasileira, constatou-se que $45 \%$ dos docentes que participaram do questionário fazem uso deste recurso, associado a materiais didáticos de outra natureza, tais como apostilas elaboradas pelos próprios docentes; textos de diferentes gêneros textuais, como "jornalísticos, artigos da área técnica ou de outras áreas, pois trabalhamos bastante na perspectiva da interdisciplinaridade, filmes, documentários, vídeos". Além disso foram mencionados materiais como datashow, textos em PDF, fotocópias, atividades compiladas de fontes diversas, outros livros didáticos, textos literários impressos, reprodução de imagens de artísticas (pintura e escultura). Foi citada a utilização do Curso de Literatura Brasileira, de Manuel Sergius Gonzaga que, embora tenha no nome literatura brasileira, traz muitas referências da Literatura Portuguesa, sempre fazendo um paralelo entre uma literatura e outra. Recursos audiovisuais, como material multimídia, também obtiveram destaque nas respostas dos professores entrevistados. Entre os docentes investigados 27,5\% afirmaram utilizar parcialmente: 
Bem, estou afastada para o doutorado desde o início do ano, mas ano passado estava utilizando a coleção do Faraco (Português: língua e cultura). Por isso, trabalhava em parte com o livro, não gostava da abordagem de trabalhar por gêneros literários, tenho uma formação bem tradicional, e gosto de trabalhar com os períodos literários, o que não me impede de trabalhar com gênero. Quando trabalho poesia com meu aluno no romantismo, ensino a estruturada da poesia, como analisar, etc. Quando chego no modernismo, retomo os conhecimentos de análise de poesia vistos no romantismo e sigo trabalhando. (R1)

A não utilização do livro didático foi verificada entre $27,5 \%$ pelas seguintes razões:

Nem todos os alunos têm o livro. Em geral, os livros que recebemos não apresentam textos literários completos, apenas trechos. (R2)

Porque elaboro o meu próprio material, a partir das bibliografias que tenho. (R3)

Infelizmente os livros didáticos ainda não conseguem ser elaborados de maneira plural e temporalmente plugadas quanto os materiais originais, produzidos com auxilio de itens disponiveis online, o que implica perdas no uso do LD. (R4)

Não há tempo hábil em aula, e em casa os alunos não leem. (R5)

Porque a base das minhas aulas é a leitura e a análise dos textos literários. (R6)

Costumo aprofundar a exploração de textos literários e, para isso, utilizo atividades autorais. Posteriormente, ao estabelecer relações entre o texto analisado e o contexto sócio-histórico-cultural, compilo textos de natureza didática, de acordo com as características da turma e meus objetivos. Assim, por não me fixar a um material didático único, não incentivo o investimento na compra massiva de livros didáticos, preferindo a aquisição de mais exemplares de obras literárias. (R7)

Primeiro porque não há exemplares suficientes para todos os alunos; segundo porque os alunos não trazem os livros que Ihes são entregues e, terceiro, porque eu prefiro elaborar o meu próprio material de trabalho, utilizando diferentes mídias e técnicas de acordo com as necessidades e dificuldades do público-alvo. R8)

Prefiro elaborar material próprio, conheço meus alunos e sei que abordagens e metodologias são mais interessantes para eles; ademais, abro para pesquisas debates o que torna a aula mais dinâmica. (R9)

A respeito da participação no processo de escolha do livro didático constatou-se que $60,7 \%$ dos docentes envolveram-se no mesmo e outros 39,3\% não participaram. Quando questionados sobre o caso de utilizar o livro didático para trabalhar a disciplina Língua Portuguesa e Literatura Brasileira nas turmas do ensino médio, as referências mais citadas foram as seguintes: Novas 
palavras, organizada Emília Amaral, Mauro Ferreira, Ricardo Leite e Antônio Severino ${ }^{11}$; Português contemporâneo: diálogo, reflexão e uso, de William Cereja, Carolina Dias Vianna e Christiane Damien ${ }^{12}$; Português: linguagens, de Thereza Cochar e William Cereja ${ }^{13}$; Português: língua e cultura, de Carlos Alberto Faraco ${ }^{14}$; Literatura brasileira: da origem aos nossos dias, de José de Nicola ${ }^{15}$; Se liga na língua: literatura, produção de texto, linguagem, de Wilton Ormundo e Cristiane Siniscalchi16; Português: contexto, interlocução e sentido, de Marcela Pontara e Maria Luiza Abaurre. ${ }^{17}$

No que se refere à edição adotada do livro didático fazer referência ao contexto histórico literário português constatou-se que 36,1\% menciona, mas de forma genérica, contendo as informações essenciais sobre a história da literatura portuguesa e seus principais autores; $22,2 \%$ a cita, apresentando breves alusões à situações históricas e autores canônicos; 16,7\% faz essa abordagem, contemplando amplamente o panorama histórico português, revisita de forma detalhada as escolas literárias que se constituíram em Portugal e apresenta as características fundamentais dos autores portugueses, clássicos e contemporâneos, propondo, inclusive, atividades que envolvam leitura e interpretação de excertos de documentos, poemas e textos em prosa; e 25\% posicionaram-se de outra forma, afirmando não se fixar nesse aspecto ou não observá-lo, por não existir preocupação com o ensino de literatura portuguesa no ensino médio.

Sobre os docentes, mesmo não utilizando o livro didático, costumarem estabelecer um paralelo entre a literatura portuguesa e a literatura brasileira, no desenvolvimento de suas aulas, constatou-se que 36,8\% trabalham nessa perspectiva, mas não de maneira sistematizada; $21,1 \%$ fazem essa relação, em situações pontuais; $7,9 \%$ não apresentam a preocupação de fazer essa abordagem; e 7,9\% não realizam essa sistematização, pois a abordagem da literatura portuguesa não está expressa do Projeto Político Pedagógico; 21,1\% posicionam-se de outra forma:

11 AMARAL, Emília; FERREIRA, Mauro; LEITE, Ricardo; ANTÔNIO, Severino. Novas palavras. São Paulo: FTD, 2016. ${ }^{12}$ CEREJA, William; DIAS VIANNA, Carolina; DAMIEN, Christiane. Português contemporâneo: diálogo, reflexão e uso. São Paulo: Saraiva, 2016.

${ }^{13}$ COCHAR, Thereza; CEREJA, William. Português: linguagens. São Paulo: Atual, 2016.

${ }^{14}$ FARACO, Carlos Alberto. Português: língua e cultura. Ensino Médio. Curitiba: Base, 2010.

${ }^{15}$ NICOLA, José de. Literatura Brasileira: da origem aos nossos dias. São Paulo: Scipione, 2011.

${ }^{16}$ ORMUNDO, Wilton; SINISCALCHI, Cristiane. Se liga na língua: literatura, produção de texto, linguagem. São Paulo: Moderna, 2016.

17 PONTARA, Marcela; ABAURRE, Maria Luiza. Português: contexto, interlocução e sentido. São Paulo: Moderna, 2016. 
Depende do período literário em questão. Os grandes autores portugueses, como Fernando Pessoa, no entanto, são importantes no meu planejamento. (R1)

Em função da carga horária exígua da disciplina, faço tal abordagem apenas quando tais relações são suscitadas, no desenvolvimento das aulas ou quando são instigadas por perguntas. (R2)

A produção literária portuguesa é importante até a Independência do Brasil. A partir daí, o foco passa a ser outras nações, além de Portugal. (R3)

Em relação à abordagem dos docentes que trabalham autores portugueses identificou-se que $34,2 \%$ dos professores incluem em suas aulas, de modo geral, todos os períodos literários, enfocando brevemente os respectivos autores e suas obras mais reconhecidas; $13,2 \%$ dos docentes não se detêm em estabelecer um paralelo entre a periodização literária; 7,9\% abordam autores modernos e contemporâneos e outros 21,1\% trabalham com outros autores que não se enquadram nos disponibilizados no questionário:

Não me detenho em estabelecer um paralelo entre a periodização literária portuguesa e brasileira, mas em determinadas situações faço referências a textos e autores portugueses. (R1)

Os autores são escolhidos de acordo com o tema das aulas. Já utilizei textos de José Saramago, Fernando Pessoa, Camões, Bocage, Eça de Queiroz, D. Diniz, Gil Vicente. (R2)

Quando preciso ilustrar que a arte reflete o contexto sócio-histórico-cultural de cada sociedade, por exemplo. (R3)

Trabalho poemas de Camões e falo sobre José Saramago. (R4)

Frente ao posicionamento dos docentes investigados percebe-se claramente que, embora o maior percentual de professores considere relevante 0 ensino da literatura, bem como 0 enfoque a ser dedicado à literatura de origem portuguesa, destacando a sua importância histórica para a formação da literatura nacional, verifica-se que a sua quase invisibilidade no ensino médio, nos dias atuais é, sob uma perspectiva, o resultado de uma construção sócio-histórica que tem suas raízes amalgamadas em um notável projeto de apagamento da cultura lusitana, o qual foi sendo aos poucos consolidado por intermédio de posições político-ideológicas que, praticamente, resultaram na supressão da disciplina de literatura, como destacam Zilberman (2002) e Perrone-Moysés 
(2006). Consequentemente, observa-se que o ensino da literatura, gradativamente, está sendo sublimado pela sua incorporação à língua portuguesa, razão pela qual muitos professores afirmam não ter tempo hábil para trabalhar conteúdos literários e preferem focar na interpretação e produção textual.

Os resultados da pesquisa mostram que os professores formados em Letras, na sua maioria, ao exercerem suas atividades docentes nos cursos técnicos integrados nos Institutos Federais acabam tendo que se adaptar à estrutura da instituição que, no ensino médio, além de prever poucos períodos destinados à Língua Portuguesa e Literatura Brasileira, não delimita, de forma clara, qual o lugar e a importância que a literatura deve ocupar na formação dos alunos, 0 que podemos confirmar diante da diversidade de posicionamentos apresentados pelos professores. Esse aspecto, embora possa ser interpretado como autonomia docente na gestão da disciplina, também nos leva a questionar quais serão as futuras direções da literatura no ensino médio.

\section{5 "A literatura em perigo" (?): considerações finais}

Em seu ensaio A literatura em perigo, Todorov apresenta o seguinte questionamento: "Como aconteceu de 0 ensino de literatura na escola ter-se tornado o que é atualmente?" Essa indagação configurou-se como um dos principais pressupostos que nortearam a realização de nossa pesquisa, que se voltou, sobretudo, para as percepções docentes a respeito da importância atribuída à literatura portuguesa, como matriz histórica a partir da qual se configurou o cânone literário nacional, e sobre as metodologias de ensino literário. O posicionamento da maioria dos professores participantes da pesquisa reflete a resposta que Todorov delineia para explicar a minimização da literatura no atual cenário educacional:

Pode-se, inicialmente, dar à questão uma resposta simples: trata-se do reflexo de uma mutação ocorrida no ensino superior. Se os professores de literatura, em sua grande maioria, adotam essa nova ótica na escola, é porque os estudos literários evoluíram da mesma maneira na universidade: antes de serem professores, eles foram estudantes (TODOROV, 2019, p. 35).

No contexto brasileiro, Zilberman (2002) indica que as razões históricas que foram apontadas para o apagamento da literatura no ensino médio incluem um projeto que se articulou 
em nome de uma postura antilusitana após a proclamação da independência, a demarcação de intelectuais que desejaram assegurar o seu espaço e brilho na construção da História da Literatura Brasileira e, para tanto, direcionaram os seus esforços para a exclusão da matriz lusitana, as inúmeras reformulações dos currículos dos cursos de Letras que, consoante a reflexão de Todorov (2019), limitaram ou extinguiram por completo a respectiva disciplina. Além disso, as sucessivas reformas no ensino médio que, cada vez mais, marginalizam os estudos literários como um todo e praticamente obscurecem a presença da literatura portuguesa, leva-nos a concordar com as palavras que Zilberman (2002, p. 41) utiliza na conclusão de seu estudo "Literatura Portuguesa no Brasil - uma estrangeira entre nós":

[...] Após a ruptura, o reatamento dos laços fica quase impossivel, a não ser que se pule, rejeite ou ignore, uma tradição já centenária. A literatura é jogada na condição do outro de que se deseja libertar, como se as amarrar coloniais, que persistem no campo econômico, embora já não sejam mais os mesmos países que manobre os cordões, pudessem ser rompidas ao âmbito cultural. $O$ pressuposto pode ser equivocado, mas persiste, e, enquanto ele se mantiver, a estrangeiridade da literatura produzida em Portugal continuará vigorando, separando o que talvez pudesse estar junto para 0 benefício de ambos.

Em relação à presença do ensino da literatura portuguesa nas escolas brasileiras toda essa conjuntura de processos históricos e manobras políticas legaram à disciplina a categoria de esquecimento que Ricoeur associa à "memória manipulada", ou seja, "uma forma ardilosa de esquecimento, resultante do desapossamento dos atores sociais de seu poder originário de narrarem a si mesmos (RICOEUR, 2007, p. 455). A função de Mnemosyne, deusa da memória, é revelar o que foi e o que está por vir. 0 esquecimento profundo, essência das águas do Lethe, também confere à memória as alternativas que possibilitam que ele seja combatido. Mas se é 0 esquecimento que torna possível a memória, assim como a expectativa apenas é possível por meio da espera, o ato de esquecer está submetido à mesma equação. Pensamos que, no caso da literatura portuguesa, a dicotomia que envolve o "esquecimento destruidor" (RICOEUR, 2007), relacionada com o processo de desvinculação de um passado colonial, e o "esquecimento-fundador" (RICOEUR, 2007), indissociável da formação do canône literário brasileiro e das políticas de ensino, continua imprecisa, pois ainda é impossível vislumbrar o ponto convergente entre o destruir e 0 construir. Espera-se, todavia, que um posicionamento crítico sobre a importância da literatura para 
a formação geral do indivíduo, tal como sugere Todorov, possa sobrepairar a todas as incongruências políticas que se projetam sobre o ensino da literatura, pois "sendo o objeto da literatura a própria condição humana, aquele que lê e a compreende se tornará não um especialista em análise literária, mas um conhecedor do ser humano" (TODOROV, 2019, p. 92).

\section{Referências}

AGUIAR, Vera Teixeira de; BORDINI, Maria da Glória. Literatura: a formação do leitor - alternativas metodológicas. Porto Alegre: Mercado Aberto, 1993.

BORDINI, Maria da Glória; AGUIAR, Vera Teixeira de. Literatura: a formação do leitor. 2. ed. Porto Alegre: Mercado Aberto, 1993.

BORDINI, Maria da Glória. Por uma fenomenologia do conhecimento literário. In: OLIVEIRA, Rejane Pivetta de (Org.). Literatura para pensar e intervir no mundo. Porto Alegre: UniRitter, 2013, v. U, p. $15-28$.

BRASIL. Base Nacional Curricular 2. Versão Revista. Brasília: Ministério da Educação, 2016.

BRASIL. PNLD. Disponível em: http://portal.mec.gov.br/component/content/article?id=12391:pnld> Acesso em: 03 jul. 2020.

CANDIDO, Antonio. Formação da literatura brasileira. Belo Horizonte: Itatiaia, 2000.

CARDOSO, Patrícia da Silva; BUENO, Luís (Orgs.). Nós e as palavras. Cotia: Ateliê Editorial, 2018.

CLEMENTE, Ir. Elvo. Por que Literatura Portuguesa? Zero Hora, Porto Alegre, 28 de janeiro de 1985 , p. 4.

DAVID, Sergio Nazar. 0 ensino da literatura portuguesa no $2^{\circ}$ grau. Idioma 18. Disponível em: http://www.institutodeletras.uerj.br/idioma/numeros/18/idioma18_a11.pdf. Acesso: em 05 fev. 2020.

ECO, Umberto. Sobre a literatura. Tradução: Eliane Junke. Rio de Janeiro: Record, 2003.

FEIJÓ, Elias J. Torres. Reorientação dos estudos literários para a aplicabilidade e a transferência: da feitiçaria para a medicina e os capitais em jogo. Revista UFG, n. 12, ano XIII, jun. 2012, p. 154173.

PERRONE-MOISÉS, Leyla. Literatura para todos, Literatura e sociedade, n. 9, 2006, São Paulo, p. $17-29$. 
RICOEUR, Paul. A memória, a história e o esquecimento. Trad. Alain François. Campinas: Unicamp, 2007.

TODOROV, Tzvetan. A literatura em perigo. Trad. Caio Meira. Rio de Janeiro: DIFEL, 2019.

VERÍSSIMO, José. A educação nacional. Rio de Janeiro: Francisco Alves, 1906.

VERISSIMO, José. História da literatura brasileira: de Bento Teixeira (1601) a Machado de Assis (1908). 4. ed. Brasília: UnB, 1963.

ZILBERMAN, Regina. Estética da recepção e história da literatura. São Paulo: Ática, 1989.

ZILBERMAN, Regina. Literatura Portuguesa no Brasil - uma estrangeira entre nós? Vidya, n. 37, jan.jun/ 2002, Santa Maria, p. 25-41.

ZILBERMAN, Regina. A universidade brasileira e o ensino das literaturas de língua portuguesa. In BORDINI, Maria da Glória; REMÉDIOS, Maria Luiza e ZILBERMAN, Regina. Crítica do tempo presente. Porto Alegre: IEL; Nova Prova, 2005.

Data de submissão: 14/08/2020. Data de aprovação: 23/10/2020. 